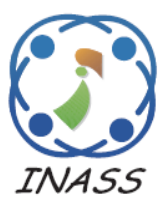

\title{
Power Management Strategy for Hybrid Energy Storage System in Hybrid Electric Vehicles
}

\author{
Nagesh Byragondlu Komarappa ${ }^{1 *}$ \\ Bangalore Rangappa LakshmiKantha ${ }^{2}$ \\ ${ }^{1}$ Reva University, Bangalore, Karnataka, India \\ ${ }^{2}$ Dayananda Sagar Academy of Technology \& Management, Bangalore, Karnataka, India \\ * Corresponding author's Email: bknp85@yahoo.com
}

\begin{abstract}
Energy Storage System (ESS) is an essential component in the Electric Vehicles (EVs) because of its high power and high energy density. In Hybrid Electric Vehicles (HEVs), the Hybrid ESS (HESS) is introduced to resolve the problem occurs due to single energy storage system. This HESS is utilized for achieving high power and energy simultaneously. In this paper, the HESS is used in HEVs to improve energy management over the vehicles. The HESS is the combination of battery and Ultra-Capacitor (UC). Here the Nickel-Metal Hydride (NiMH) battery is used as a primary energy source and UC is used as a secondary energy source. The energy management over the HEVs made by an effective Artificial Neural Network (ANN) based controller which is utilized for handling the charging and discharging operation of the ultra-capacitor. The operating mode of UC using ANN is mainly based on the State of Charge (SOC) from the battery at each iteration. The UC is on, when the SOC of the battery is less than $60 \%$, it shows that the battery does not have the capacity to achieve the load requirement of Permanent Magnet Synchronous Motor (PMSM). The performance of the proposed system analysed in terms of speed, torque and current. Then it evaluated by using the system with ANN and without ANN. The motor speed and vehicle speed of the HEV with ANN at 70 Sec improved $8 \%$ and $9.38 \%$, respectively compared to the HEV without ANN.
\end{abstract}

Keywords: Artificial neural network controller, Hybrid energy storage system, NiMH battery, Permanent magnet synchronous motor, Ultra-capacitor.

\section{Introduction}

Energy Storage Systems (ESSs) are utilized in various applications like uninterruptable power supplies, wireless communications, renewable energy systems and in industrial applications as well as it is important in Electric vehicles (EV), Hybrid Electric Vehicles (HEVs) and Plug-in Hybrid Electric Vehicles (PHEVs) [1-2]. One of the energy storage device in electric vehicles is Super-capacitors (SCs) or Ultra-capacitors (UCs) and it is called as Electric Double Layer Capacitors (EDLCs) [3]. The single ESS does not have the capacity to meet the power and energy requirements of the EVs without affecting their own lifetime. To overcome this issue, more than one ESS used in EV which is named as Hybrid ESS (HESS) [4]. Here, the proper energy storage system over the vehicles are must, because of the environmental concerns and price of the petroleum [5]. In an electric vehicle, batteries are used as a main energy storage component for providing the energy and power demand of the car [6]. The battery is the most common devices of ESS and this is mainly used for light duty vehicles [7]. Generally, the HEVs uses two or more power sources for the drive system. Besides, the vehicle with a single power source uses an internal combustion engine (ICE) which consists of a reciprocating engine (i.e., typically fuelled by gasoline) [8].

The most commonly used ESS in HEVs are batteries and UCs. UCs have only less energy compared to the batteries. Higher amount of energy in battery propels the vehicle for a longer time [9-10]. In the short time interval, the UC delivers peak power compared to the conventional energy sources such as engine, battery, fuel cell, etc. The UCs with HESS improves the lifetime and reliability of the power 
system [11]. The UCs are utilized as a pulse power device. In this UC, the energy flow in/out of the device at driveline operation. However, the batteries of ESSs use in two different ways. It can use an energy storage unit with state of charge which is consumed over time and one more use is a pulse power device in a relatively narrow range of state of charge [12]. The Regenerative Breaking (RB) is introduced for improving the range in all EVs and also it eliminates the energy storage oversize. This $\mathrm{RB}$ achieves the electrical energy from the vehicle's kinetic energy and the electrical energy transfer into the EVs. Here, the Energy Management System (EMS) is required to absorb the higher amount of energy which is produced by RB [13]. Some of the conventional methods used in HEVs based ESS are given as follows: Energy management strategy in two propulsion based powertrain by using fuzzy-logic supervisory WT-based frequency decoupling strategy [14]. Accurate DC bus voltage regulation and the battery and UC current to the reference values are rapidly tracked by Lyapunov theory [15]. The future load demand of the vehicle is identified by the predictive algorithm which utilizes state based approaches inspired from power systems optimization [16].

The major contributions of this paper are stated as follows:

- The effective power distribution to the HEV is performed by using two different energy sources such as battery and ultra-capacitor in HESS.

- Here the ANN based controller is used for enabling the charging and discharging of the UC. The UC discharg the power, when the battery doesn't have enough power to compensate the HEV load requirement.

- In this case, the effective power is given to the HEV as well as this proposed methodology gives better torque.

This research work is composed as follows, Section-2 presents an extensive survey recent papers based on HEV. In the section-3, briefly described the ANN using energy management strategy in HEV. The section-4 describes about an experimental result of a ANN based energy management strategy in HEV. The conclusion of this research work is given in the section-5.

\section{Literature survey}

H. Marzougui [17] presented the energy management algorithm for electrical hybrid vehicle. The fuel cell used as the main energy source in the hybrid vehicle and the storage system consists of ultra-capacitor and battery. Here, the fuel cell (i.e., main source) produced essential energy for EV. The lacking power produced and excess power absorbed during the operation of acceleration and braking respectively. The power from the three energy sources accurately regulated by determining the converters current using energy management algorithm. The DC/DC bidirectional current converter converts the variable voltage into constant voltage at battery. The energy management used in the hybrid vehicle is only based on the distributing energy flux among the sources of the electric vehicle.

A. Florescu [18] introduced the adaptive frequency based power sharing between the power sources of batteries and UCs. The low frequency and high frequency content of power demand routed into the battery and the UC system respectively by using an adaptive frequency splitter. The PMSM performed electric traction and this PMSM controlled either as a motor (at accelerating) or as a generator (at braking). The 3 phase voltage source inverter coupled with DClink to control the torque. The energy separation between the battery and UC performed by low pass filter and the folding frequency of this filter depends on the SOC of UC and the modes of the source. The huge variations of the voltage occurred when the discharging of the UC happened in the electric vehicles.

H. Yin [19] presented the adaptive fuzzy logic based energy management strategy (AFEMS) in HEVs. Based on the previous driving patterns, the AFEMS identifies the optimal membership function by offline optimization and online tuning. Here, the parallel active topology selected as a vehicle system because it resolves the DC link voltage matching problem between the UC pack, load and battery pack. This AFEMS processed by three different inputs such as power demands, vehicle driving modes and SOC of UC. The driving modes classified into four types such as low speed, medium speed, high speed and super high speed. The energy loss in the battery internal resistor is high, when there is a rise in discharging current.

J. Jeong [20] presented HEV by using three power sources such as engine, battery and ultracapacitor. The optimal power distribution among three power sources selected by two states and two control variables from the dynamic programming and optimization theory. But the dynamic programming needs unreasonable amount of calculations. The potential fuel economy of the vehicle determined by dynamic programming. Based on the required optimal energy, the optimization of power between the battery and UC was calculated. The fuel economy 
of developed algorithm is not better, compared to the general optimized algorithm.

B. Wang [21] introduced the HESS and its energy management strategy for EVs. The energy management strategy improved by rule based control strategy and power balancing strategy and it used for realizing the power distribution and mode selection. The energy from the battery transferred to UC by DCDC converter. Here, the multimode HESS selects the pre battery mode for achieving the low power demands. Moreover, the HESS has pure UC mode, pre battery mode, recycle mode and hybrid output mode, etc. The voltage fluctuation occurred in the vehicles, when the improper mode is selected in the HESS.

K. Gokce and A. Ozdemir [22] presented an efficient rule based control strategy to the combined battery/UC ESS. The SOC level of energy sources were formulated the weighting parameters of rule table. The charging and discharging were defined by both the weighting parameters and states of energy sources. The battery and UC present in the electric vehicles were protected from high temperature rise and high current pulses. In this rule based control strategy, the battery is less exposed to the rapid current changes.

\section{HESS design considerations}

In this section, the basic design considerations for the development of battery/UC HESS topologies are discussed.

\subsection{Voltage strategy of the two energy sources}

The voltage strategy selection in battery/UC HESS design is mainly related to the characteristics of the UCs and battery. For the cell balancing circuit, a higher demand presents by energy storage device of higher voltage capacity. Because the cell imbalances extended by the amount of cells in series. The cells with low performance variations are required for decreasing the balancing. Typically, the bigger patch of cells needs to be selected for a better matched performance. The voltage trade-off among the storage elements occurred based on the characteristics of UC cells and battery. Here, the ultra-capacitors are easy to balance with low additional cost. The HESS topology is based on the selection of voltage strategy. The voltage of the UC, battery and DC link are represented as $V_{U C}, V_{b a t t}$ and $V_{D C}$ respectively. The battery is connected to the DC link and also the UC is connected to the DC link via DC/DC converter, when the $V_{U C}<V_{b a t t}=V_{D C}$. The high power capability of the UC is fully utilized by matching the DC/DC power converter with UC.

The UC's entire range is utilized when the voltage UC bank is required, which is the major advantage of the voltage strategy. The positions of the battery and the UC are switched when $V_{b a t t}<V_{U C}=V_{D C}$. The $\mathrm{UC}$ bank is directly connected to the DC link, while the battery is linked to the DC link via a DC/DC converter. In this case, the battery voltage is maintained in lower magnitude so that the less balancing issues are required to be addressed. The $\mathrm{UC}$ and battery are directly paralleled and connected to the DC link, so the $V_{b a t t}=V_{U C}=V_{D C}$. The $\mathrm{DC} / \mathrm{DC}$ converter is not required in HEV, when the operating range of UC is very small. Then the battery and UC connect to the DC link via power electronic converters or other mechanisms only when $V_{\text {batt }} \neq$ $V_{U C} \neq V_{D C}$. If the condition $V_{\text {batt }} \neq V_{U C} \neq V_{D C}$ is satisfied, the DC link is connected with the battery and UC through power electronic converters or other mechanisms.

\subsection{Protection of the battery from overcurrent}

The design of battery/UC HESS uses high power limits of the UC for supporting the acceleration as well as it recovers the whole energy via regenerative braking. Typically, the frequent charges are current surges which are created by unpredictable regenerative breaking. The lifetime of the battery is very less, when the current surge injected directly to the battery. This is specifically true for lithium ion batteries. The issue due to current surge overcome by providing the charging and discharging limits to the controller. This permits the hybrid system optimizer to follow the power limits to protect the battery. In discharging power limits, there is no extra power drawn from the battery during aggressive acceleration. But in charging power limits, the hybrid power controller force to activate the mechanical brake for absorbing the additional energy. This process is a trade-off where energy is utilized for the security of the battery pack.

\section{Proposed methodology}

A control strategy for the HESS is introduced using the SOC of the battery and UC to balance the energy in HESS. Furthermore, the HEV requires regulated EMS to manage higher efficiency motor and maintain the real-time charging/discharging capability of HESS. 


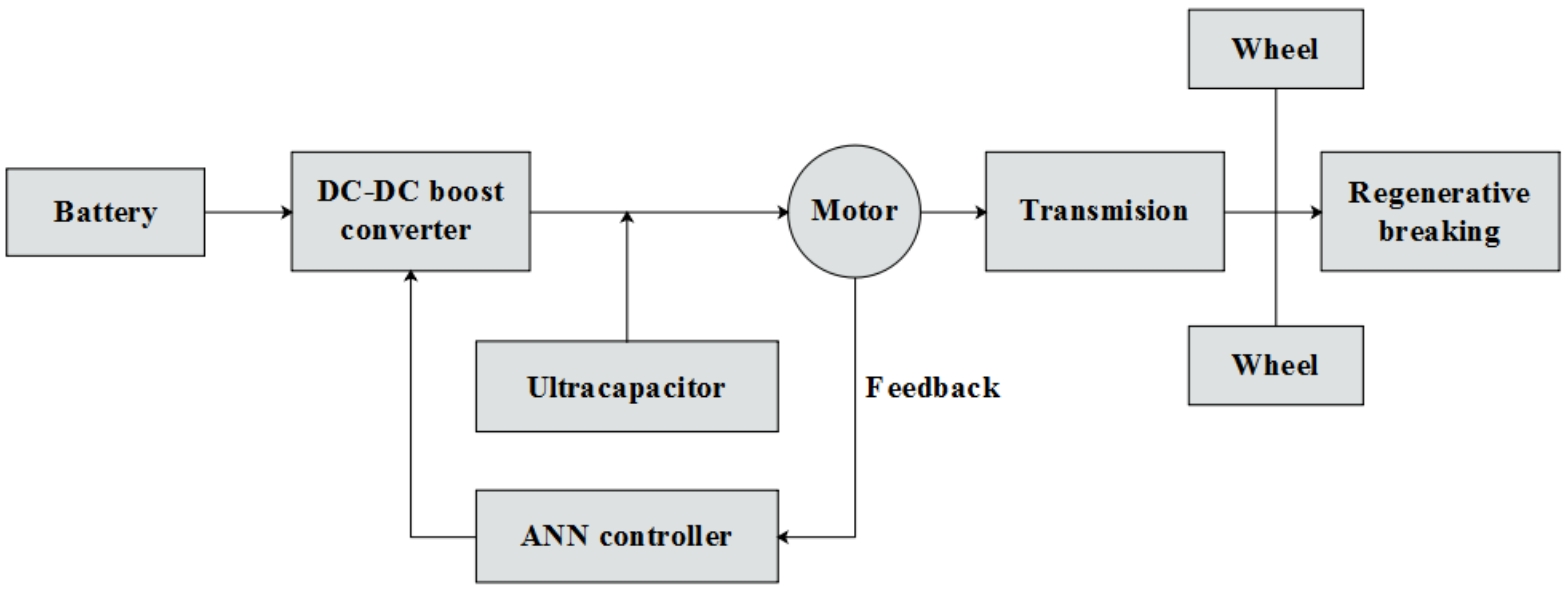

Figure.1 Block diagram of the proposed system

The main components of the proposed system are battery, Ultra-capacitor, DC-DC buck/boost converter, motor, ANN controller, wheel and regenerative braking. The following Fig. 1 shows the block diagram for the proposed system. Here, the battery is connected as a primary energy source and UC works as a buffer against large magnitudes and rapid fluctuations in power, whereas the battery connected to DC/DC is protected and the energy flow can be effectively controlled. The battery is working as a main source which provides supply to the whole system. Whereas, DC-DC converter maintain the power balance between battery and UC. The motor is used as a load to evaluate the performance of the complete system. The working condition of the system is stable by providing chemical energy via motor speed. The operating condition of UC is defined by the feedback from the motor and the control strategy maintain the charging/discharging capability of US in HESS.

\subsection{Nickel-metal hydride battery model}

The NiMH battery is used as a primary energy source in HEV. This NiMH battery use the electrolyte (alkaline solution) and contains positive electrode and negative electrode. The positive electrode and negative electrode are nickel Oxy-hydroxide and metal hydride respectively. In charge reaction, the water and $\mathrm{NiOOH}$ is formed when the hydroxide of electrolyte reacts with positive electrode. In negative electrode, the metal hydride formed by the reaction of water with metal alloys. The charge reaction is named as exothermic. The continuous temperature rises of the cells eliminated by releasing the heat which produced in the charge process. The basic cell reaction of the NiMH battery is expressed in the Eq. (1).

$$
\mathrm{M}+\mathrm{Ni}(\mathrm{OH})_{2} \leftrightarrow \mathrm{MH}+\mathrm{NiOOH}
$$

The Fig. 2 shows the equivalent circuit of the NiMH battery. Where the no load voltage and constant voltage are denoted as $E$ and $E_{0}$ respectively. $K$ is the polarization resistance or constant. $q$ is the exponential voltage. The parameters of equivalent circuit type depend on the discharge characteristics.

The State of Charge (SOC) of the battery is between $0 \%$ to $100 \%$. The SOC for an empty battery and a fully charged battery are $0 \%$ and $100 \%$ respectively. The SOC for a NiMH battery is defined in the Eq. (2).

$$
S O C=100\left(1-\frac{q \cdot 1.05}{\int i . d t}\right)
$$

The NiMH battery energy density is high compared to the lead acid battery. The components of the battery are harmless to the environment as well as this NiMH can be recycled and it can be operated even in high voltage safely.

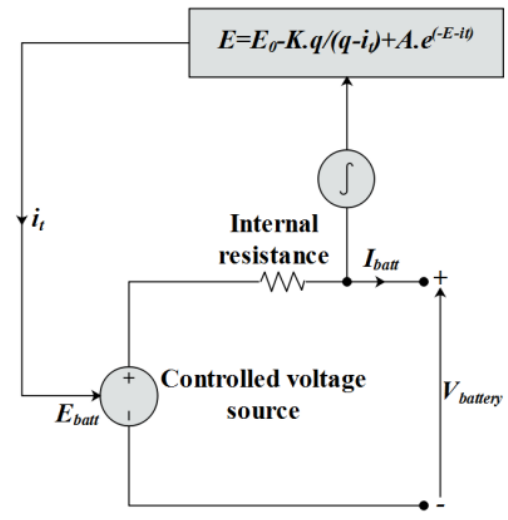

Figure.2 Equivalent circuit of the NiMH battery 
This battery has several advantages like power, long cycle life, resistance to on charge and discharge, wide operation temperature ranges and storing volumetric energy. This battery is connected to the motor through DC-DC boost converter. Here, DC$\mathrm{DC}$ boost converter is used for balancing the power consumption between the battery and the UC.

\subsection{Ultra-capacitor}

UC is used as a secondary energy source. This UC is in active mode, when the load requirement of the motor is high as well as it is used to compensate the load requirement of HEV's. The ANN controller helps to control the charging and discharging conditions of the UC. UCs are also known as super capacitor or electrochemical capacitor and this UC's has high energy density. The unit of the ultracapacitor is Farads $(\mathrm{F})$ and it is high compared to the conventional fuel in the range of milli-farads $(\mathrm{mF})$ to Pico farads $(\mathrm{pF})$. The power and energy density of the UC are $10^{6} \mathrm{~W} / \mathrm{m}^{3}$ and $10^{4} \mathrm{Wh} / \mathrm{m}^{3}$ respectively. This UC charges and discharges efficiently, quickly and its lifetime are high. The capacitance values of UC are the order of the magnitude that is high compared to the regular capacitors.

The rapid charging and discharging characteristics of UC is helpful to provide the huge amount of energy in HEV's. The equivalent circuit for a UC is composed of a network of resistors and capacitors which is given in the Fig. 3. Here, the resistors $\left(R_{1}, R_{2}\right.$ and $\left.R_{3}\right)$ and capacitors $\left(C_{1}, C_{2}\right.$ and $\left.C_{3}\right)$ are fixed resistances and capacitances respectively.

The capacitance of capacitor $C_{V}$ is based on the voltage across it. The voltage through the individual fixed capacitor is computed by an Eq. (3).

$$
V_{c}=\frac{V}{N_{\text {series }}}-i_{n} R_{n}
$$

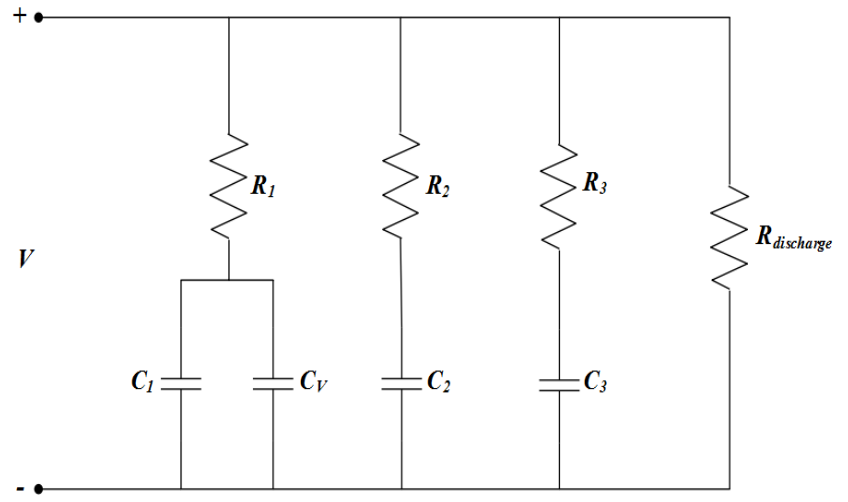

Figure.3 Equivalent circuit for Ultra capacitor
Where, voltage across the block is $V$, amount of cells in series is $N_{\text {series }}$, the branch number is $n=$ $[1,2,3]$. The current via the $n^{\text {th }}$ branch is $i_{n}$ and resistance in the $n^{\text {th }}$ branch is $R_{n}$.

\subsubsection{Charging and discharging behaviour of Ultra- capacitor}

To charge the UC, a current of $100 \mathrm{~mA}$ is given as the input to the UC for 100 seconds. The UC is then rested for one minute. For the next hour, to discharge the UC, a load of $50 \mathrm{~mA}$ is stepped on for one second in every 50 seconds. The UC is then rested until the end of the simulation.

\subsection{Model of permanent magnet synchronous motor}

The mathematical model of PMSM motor is similar to the wound rotor synchronous motor. In PMSM, there is no external source connected to the rotor side and the variation which is produced in the rotor flux related to time is negligible. The model of the PMSM is derived from the rotor reference frame. The electrical dynamic equation of PMSM in terms of phase variables is given in Eq. (4).

$$
\begin{aligned}
& v_{a}=R_{a} i_{a}+p \lambda_{a} \\
& v_{b}=R_{b} i_{b}+p \lambda_{b} \\
& v_{c}=R_{c} i_{c}+p \lambda_{c}
\end{aligned}
$$

Where the phase variables of PMSM are $v_{a}, v_{b}$ and $v_{c}$. The flux linkages such as $\lambda_{a}, \lambda_{b}$ and $\lambda_{c}$ of Eq. (4) are given in the Eq. (5).

$$
\begin{aligned}
& \lambda_{a}=L_{a a} i_{a}+L_{a b} i_{b}+L_{a c} i_{c}+\lambda_{m a} \\
& \lambda_{b}=L_{a b} i_{a}+L_{b b} i_{b}+L_{b c} i_{c}+\lambda_{m b} \\
& \lambda_{c}=L_{a c} i_{a}+L_{b c} i_{b}+L_{c c} i_{c}+\lambda_{m c}
\end{aligned}
$$

Consider, the symmetry of mutual inductances such as $L_{a b}=L_{b a}$, self-inductances $L_{a a}=L_{b b}=$ $L_{c c}$ and the flux linkage $\lambda_{m a}=\lambda_{m b}=\lambda_{m c}=\lambda_{m}$. The set of simple transformed equation from Eq. (4) and (5) is given in the Eq. (6).

$$
\begin{aligned}
& v_{q}=\left(R_{s}+L_{q} p\right) i_{q}+\omega_{r} L_{d} i_{d}+\omega_{r} \lambda_{m} \\
& v_{d}=\left(R_{s}+L_{d} p\right) i_{d}-\omega_{r} L_{q} i_{q}
\end{aligned}
$$

Where, $L_{q}$ and $L_{d}$ are inductances of $q$ and $d$ axis respectively; motor electrical speed is $\omega_{r}$.

The self-inductance and contributions from other two phase currents are used to create inductance. The following Eq. (7) represents the electromagnetic torque $T_{e}$. 


$$
T_{e}=(3 / 2)(P / 2)\left(\lambda_{m} i_{q}+\left(L_{d}-L_{q}\right) i_{d} i_{q}\right)
$$

Where, the number of pole pairs are represented as $P$ and stator flux linkage is $\lambda_{m}$. The stator flux linkage is generated because of the permanent magnets. The torque from the Eq. (7) is composed of two distinct mechanisms. In the Eq. (7), the first term represents the mutual reaction torque occurring between $i_{q}$ and the permanent magnet. Then the second term represents the inductance torque due to the differences in $\mathrm{d}$ axis and q-axis inductance.

The electromagnetic torque of Eq. (7) is balanced by using damping torque, load torque an accelerating torque. Then electromagnetic torque of Eq. (7) is modified and it is expressed in Eq. (8).

$$
T_{e}=J p \omega_{r}+B \omega_{r}+T_{l}
$$

Where, the moment of inertia is $J$, damping coefficient is $B$ and the load torque is $T_{l}$.

\subsubsection{Vector control of PMSM}

Vector control is also called as decoupling or field oriented control. This vector control is used to decouple the one producing flux, torque and three phase stator current into two phase $\mathrm{d}-\mathrm{q}$ axis current and also it allows direct control of flux and torque. The PMSM is identical to the excited DC machine by utilizing the vector control. The vector control scheme depends on the motor torque equation and coordinate transformation. The performance of the motor is enhanced by handling the stator current. The rotated magnetic field is built and driven by providing the modulated current to the ABC stator windings in the three phase PMSM system control. The reference frame is rotated synchronously by formulating the vector control strategy. The required air gap is produced by designing the PMSM with rotor magnet alone. The constant air gap flux is required to rated speed. The information about the instantaneous rotor flux is required in the vector control to handle the PWSM in an effective manner.

\subsection{ANN controller}

The overall model of the proposed system is illustrated in Fig. 1. This ANN is enabled the UC when the SOC of the battery goes below $60 \%$. The SOC of the battery is obtained from the Eq. (2). Depending on the load requirement in HEV, the SOC of the battery varies. Here, the Ultra-capacitor is used to compensate the load requirement when the $\mathrm{HEV}$ has high load requirement. In this proposed system, the ANN controller is used for controlling on/off of the UC to provide the essential power to the motor.
ANNs are certified as an intelligent computing tolls, it is made from multiple interconnected components which are called as neurons. These neurons determine the underlying relationship between the input and output patterns. The ANN performance mainly depends on the design process. Initially, the all possible cases of the HEV need to be trained by ANN. Then the type of the ANN, amount of hidden layers and neurons required to select the operating modes of the UC. Based on the collected data (battery's SOC) from the battery, the ANN is trained. Further, the trained ANN is evaluated by using the battery's SOC at each time. The output of the ANN is in the form of either 0 or 1 . With that, the 1 describes the on condition of UC and 0 describes the off condition of $\mathrm{UC}$. The UC is on only when the battery does not have the essential power to operate the motor of $\mathrm{HEV}$.

\section{Results and discussion}

The simulation of the proposed methodology is performed using the MATLAB/SIMULINK R2018a. The analysis of HESS in HEV is made by using the two different energy sources such as battery and ultra-capacitor. The type of battery used in this proposed methodology is Nickel Metal Hydride battery. Here, the permanent magnet synchronous motor is used as the HEV load. Then ANN controller is utilized to perform charging/ discharging of the UC, it depends on the SOC of the battery. The specifications of the battery, UC and motor are given in the Table 1, 2 and 3 respectively. HESS is simulated for a fixed load (i.e., PMSM motor) with the time duration of 200 seconds. The performance of the proposed methodology is analysed in terms of SOC of the battery, torque, speed of the motor and HEV.

Table 1. Specifications of the battery

\begin{tabular}{|c|c|}
\hline Maximum capacity (Ah) & 8.7231 \\
\hline Cut off voltage (V) & 150 \\
\hline Fully Charged Voltage (V) & 235.5932 \\
\hline Nominal discharge current (A) & 1.62 \\
\hline Initial State of Charge (\%) & 100 \\
\hline Internal resistance (Ohms) & 0.24691 \\
\hline Energy Capacity (Ah) at nominal voltage & 7.7885 \\
\hline Exponential zone [Voltage (V), Capacity & 216.9492, \\
(Ah)] & 1.62 \\
\hline Discharging current [i1, i2] (A) & 50,100 \\
\hline Volumetric energy density (Wh /L) & $200-250$ \\
\hline
\end{tabular}

Table 2. Specifications of the Ultra-capacitor

\begin{tabular}{|c|c|}
\hline Resistances $(\mathrm{Ohms})\left[R_{1}, R_{2}, R_{3}\right]$ & $0.2,90,100$ \\
\hline Capacitances $(F)$ & $2.5,1.5,4$ \\
\hline Voltage dependent capacitor gain & 0.95 \\
\hline Initial Voltage $(\mathrm{V})$ & 16 \\
\hline
\end{tabular}


Table 3. Specifications of the PMSM motor of HEV

\begin{tabular}{|c|c|}
\hline Voltage (V) & 500 \\
\hline Power rating (KW) & 50 \\
\hline Speed (rpm) & 3500 \\
\hline Number of pole pairs & 4 \\
\hline Stator phase resistance (ohm) & 0.18 \\
\hline Armature inductance $(\mathrm{H})$ & 0.000835 \\
\hline Flux linkage & 0.175666143629361 \\
\hline
\end{tabular}

The Simulink model of the proposed methodology is given in the Fig. 4. The major components of this model are Ni-MH battery, ultracapacitor, $\mathrm{HEV}$, and ANN controller. Initially, $\mathrm{NiMH}$ battery provides the essential energy to the $\mathrm{HEV}$, because this NiMH battery is used as the main source. After that, the UC is utilized when the SOC of the battery is lesser than $60 \%$, it is handled by using ANN controller.

The above Fig. 5 shows the NiMH battery discharge characteristics of nominal current. Where, the constant voltage is $E 0$, the internal resistance is $\mathrm{R}$; polarization current is $K$; exponential voltage is $A$; exponential capacity is $B$. The values of the $E 0, R, K$, $A$ doubled as nominal voltage, when the $B$ depends on the type of the battery.

Fig. 6 shows the SOC of the battery, when the HEV with and without ANN controller. SOC is defined as the available capacity (in Ah) and it is expressed as the percentage of its rated capacity. The SOC estimation of the battery avoids unpredicted system interruption and prevent the batteries from being over charged and over discharged, which may cause permanent damage to the internal structure of batteries. From the Fig. 6, it concluded that the SOC of the battery improved when the ANN controlled the charging and discharging characteristics of the UC. The lifetime of the proposed methodology is high compared to the HEV without ANN controller. The Fig. 6 shows the SOC of the battery goes to zero after $60 \mathrm{Sec}$. At that time, the ultra-capacitor is turned on by the ANN controller to provide the essential power to the HEV. The SOC of the ultra-capacitor is shown in the following Fig. 7.

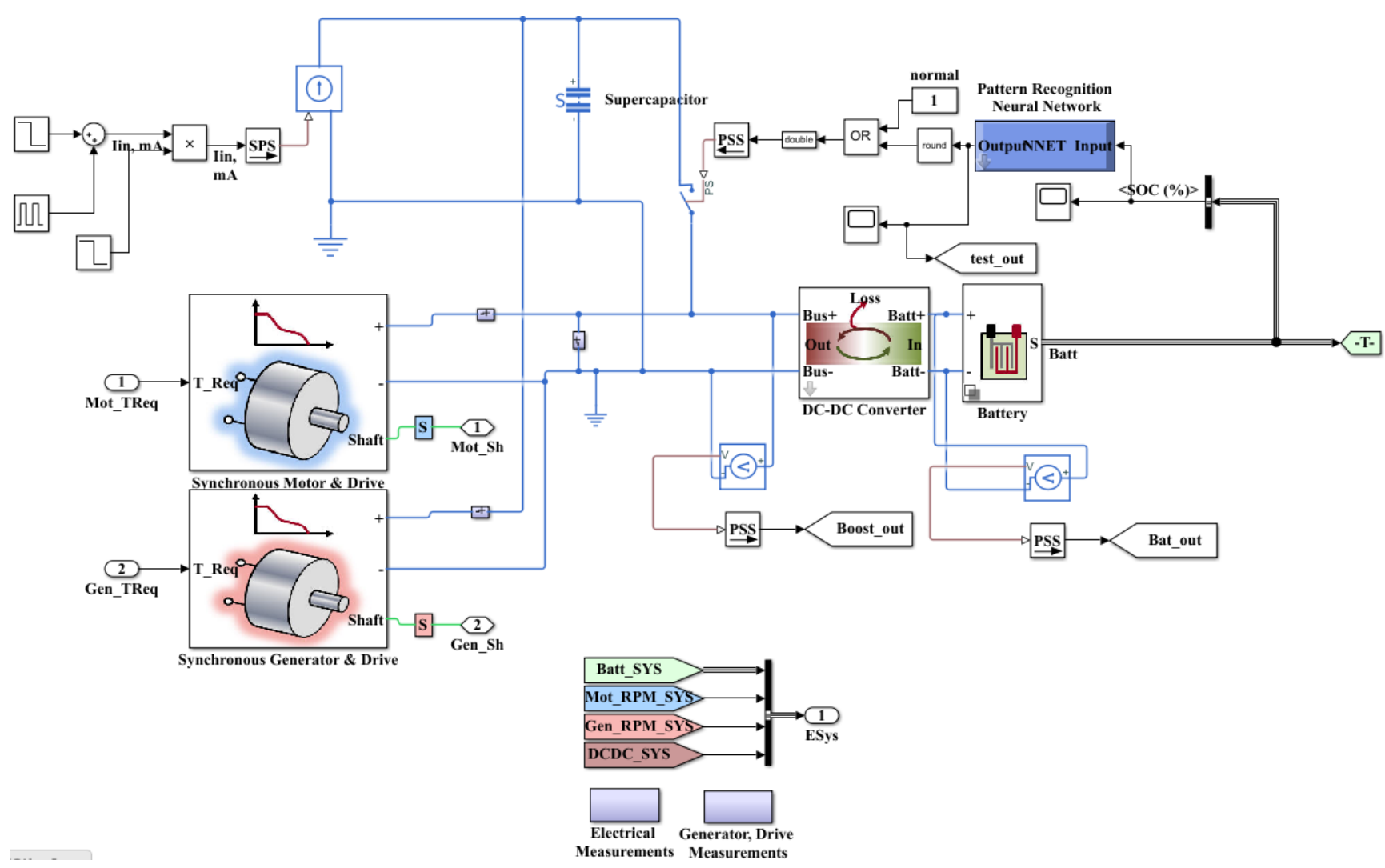

Figure.4 Simulink model for the proposed methodology. 

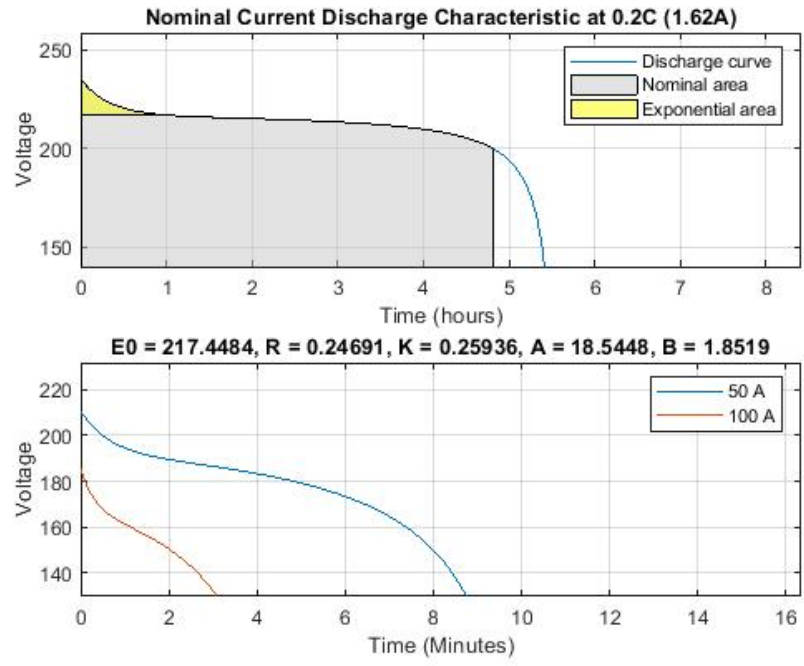

Figure.5 Nominal current discharge characteristics

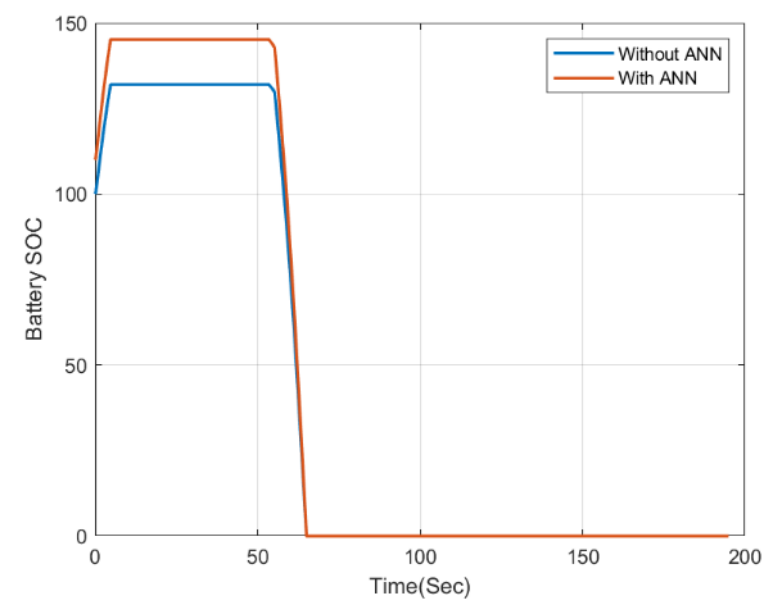

Figure.6 Comparison of battery SOC

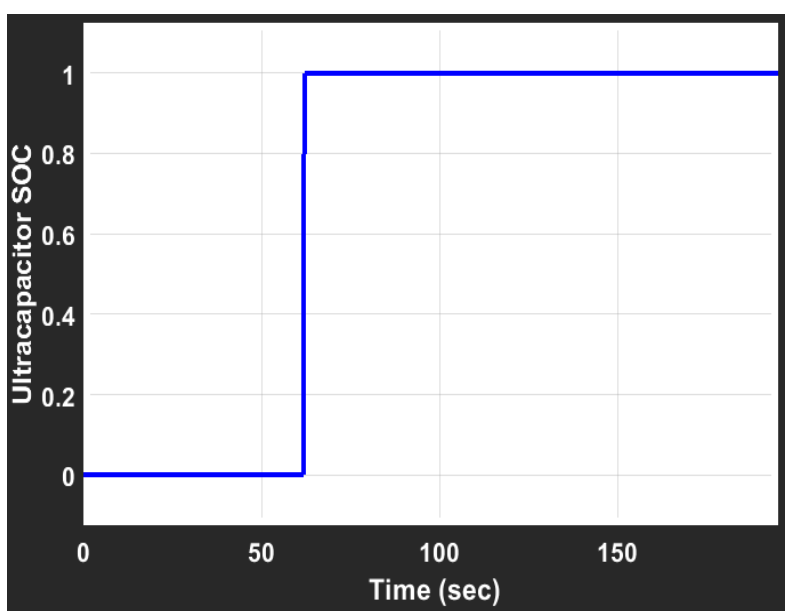

Figure.7 SOC of the ultra-capacitor

Fig. 8 presents the vehicle's speed of HEV with and without ANN controller. The vehicle's speed describes the overall speed of the HEV which moves in real time. The vehicle's speed of the HEV with ANN controller is maximized when compared to the HEV without ANN.

Fig. 9 shows the comparison of HEV torque with and without ANN controller. The torque depends on the desired and actual vehicle's operating conditions such as vehicle speed and road slope. The torque $(\tau)$ is calculated by using the following Eq. (9).

$$
\tau=R_{f} \times T T E \times r_{\text {wheel }}
$$

Where, $R_{f}$ is the friction factor that accounts for frictional losses among bearings, axles, etc., TTE is the total tractive effort and $r_{\text {wheel }}$ is the radius of drive wheel. The torque is high when the HEV has the ANN controller to control the charge/discharge characteristics of the UC.

Fig. 10 shows the comparison of HEV motor speed with and without ANN controller. This motor speed describes the amount of the speed in RPM obtained from the engine of the PMSM motor. The value of the motor speed without ANN is less compared to the HEV with ANN controller.

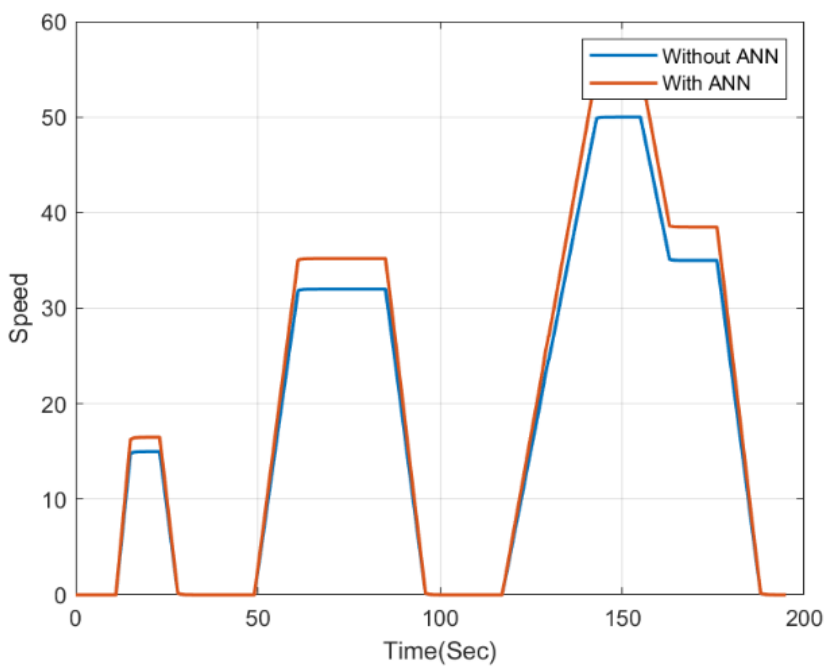

Figure.8 Comparison of vehicle's speed

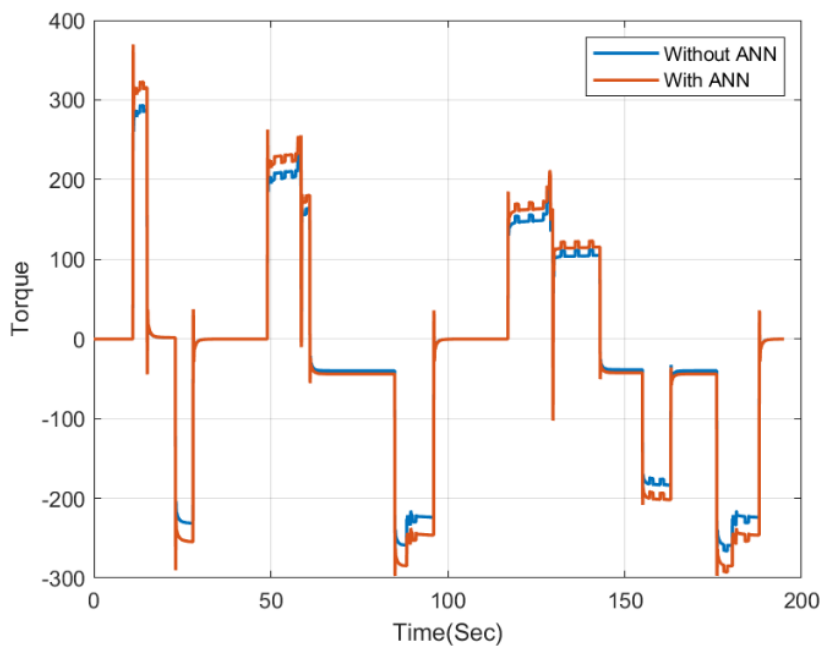

Figure.9 Comparison of torque 


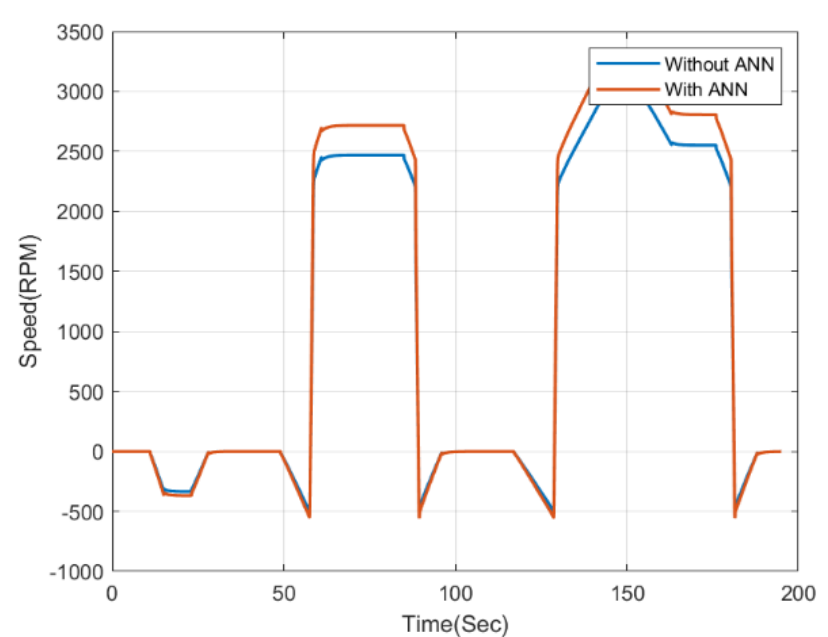

Figure.10 Comparison of motor speed

Table 4. Comparative analysis

\begin{tabular}{|c|c|}
\hline Methods & Vehicle's max speed (km/h) \\
\hline ANN based HESS & 54 \\
\hline Manhattan cycle [22] & 40 \\
\hline UDDS cycle [22] & 32 \\
\hline
\end{tabular}

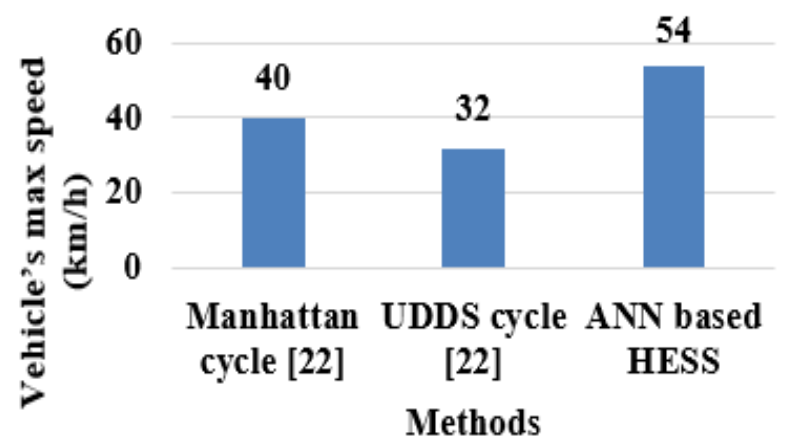

Figure. 11 Comparison of vehicle's maximum speed

The vehicle speed of the proposed ANN based HESS was compared with rule based control strategy [22]. The rule based control strategy [22] analysed in two different cycles such as Manhattan cycle, UDDS cycle. The comparative analysis of ANN based HESS is given in the following Table 4 and Fig. 11.

\section{Conclusion}

In this paper, an ANN controller based HESS model is developed by using the combination of NiMH battery and ultra-capacitor in HEV. Both the battery and ultra-capacitor used as a source for the $\mathrm{HEV}$. In that the battery used as the primary source and UC used as the secondary source. The battery power is not enough, when the load requirement of $\mathrm{HEV}$ is too high. In this case, the UC is utilized to compensate the HEV load requirement. The charging and discharging characteristics of the UC is handled by the ANN controller. The discharging of the UC occurred when the SOC of the battery goes lesser than $60 \%$. The SOC of the battery monitored in each iteration to predict when the UC needs to be on/off. Based on this, the essential power to the HEV delivered in each iteration. From the results, conclude that the ANN with the HEV gives better performance compared to the HEV without ANN controller. In future, the battery life of the HEV can be maximized by using the optimization technique.

\section{References}

[1] L. Zhang, X. Hu, Z. Wang, F. Sun, and D.G. Dorrell, "Experimental impedance investigation of an ultracapacitor at different conditions for electric vehicle applications", Journal of Power Sources, Vol.287, pp.129-138, 2015.

[2] J. Cao and A. Emadi, "A new battery/ultracapacitor hybrid energy storage system for electric, hybrid, and plug-in hybrid electric vehicles", IEEE Transactions on power electronics, Vol.27, No.1, pp.122-132, 2012.

[3] L. Zhang, X. Hu, Z. Wang, F. Sun, and D.G. Dorrell, "A review of supercapacitor modeling, estimation, and applications: A control/management perspective", Renewable and Sustainable Energy Reviews, Vol.81, pp.1868-1878, 2017.

[4] R. Xiong, H. Chen, C. Wang, and F. Sun, "Towards a smarter hybrid energy storage system based on battery and ultracapacitor-A critical review on topology and energy management", Journal of Cleaner Production, Vol.202, pp.1228-1240, 2018.

[5] A. Demircal1, P. Sergeant, S. Koroglu, S. Kesler, E. Öztürk, and M. Tumbek, "Influence of the temperature on energy management in batteryultracapacitor electric vehicles", Journal of Cleaner Production, Vol.176, pp.716-725, 2018.

[6] J. Shen and A. Khaligh, "A supervisory energy management control strategy in a battery/ultracapacitor hybrid energy storage system", IEEE Transactions on Transportation Electrification, Vol.1, No.3, pp.223-231, 2015.

[7] A. Ostadi and M. Kazerani, "A comparative analysis of optimal sizing of battery-only, ultracapacitor-only, and battery-ultracapacitor hybrid energy storage systems for a city bus", IEEE Transactions on Vehicular Technology, Vol.64, No.10, pp.4449-4460, 2015.

[8] Q. Li, W. Chen, Y. Li, S. Liu, and J. Huang, "Energy management strategy for fuel cell/battery/ultracapacitor hybrid vehicle based on fuzzy logic", International Journal of Electrical Power \& Energy Systems, Vol.43, No.1, pp.514-525, 2012. 
[9] R.T. Doucette, and M.D. McCulloch, "A comparison of high-speed flywheels, batteries, and ultracapacitors on the bases of cost and fuel economy as the energy storage system in a fuel cell based hybrid electric vehicle", Journal of Power Sources, Vol.196, No.3, pp.1163-1170, 2011.

[10] P. Bubna, S.G. Advani, and A.K. Prasad, "Integration of batteries with ultracapacitors for a fuel cell hybrid transit bus", Journal of Power Sources, Vol.199, pp.360-366, 2012.

[11] M.R. Kumar, S. Ghosh, and S. Das, "Chargedischarge energy efficiency analysis of ultracapacitor with fractional-order dynamics using hybrid optimization and its experimental validation", AEU-International Journal of Electronics and Communications, Vol.78, pp.274-280, 2017.

[12] A. Burke and M. Miller, "The power capability of ultracapacitors and lithium batteries for electric and hybrid vehicle applications", Journal of Power Sources, Vol.196, No.1, pp.514-522, 2011.

[13] J. Armenta, C. Núñez, N. Visairo, and I. Lázaro, "An advanced energy management system for controlling the ultracapacitor discharge and improving the electric vehicle range", Journal of Power Sources, Vol.284, pp.452-458, 2015.

[14] S. Dusmez and A. Khaligh, "A supervisory power-splitting approach for a new ultracapacitor-battery vehicle deploying two propulsion machines", IEEE Transactions on Industrial Informatics, Vol.10, No.3, pp.19601971, 2014.

[15] H. Armghan, I. Ahmad, N. Ali, M. F. Munir, S. Khan, and A. Armghan, "Nonlinear Controller Analysis of Fuel Cell-Battery-Ultracapacitorbased Hybrid Energy Storage Systems in Electric Vehicles", Arabian Journal for Science and Engineering, Vol.43, No.6, pp.3123-3133, 2018.
[16] O. Laldin, M. Moshirvaziri, and O. Trescases, "Predictive algorithm for optimizing power flow in hybrid ultracapacitor/battery storage systems for light electric vehicles", IEEE Transactions on power electronics, Vol.28, No.8, pp.38823895, 2013.

[17] H. Marzougui, M. Amari, A. Kadri, F. Bacha, and J. Ghouili, "Energy management of fuel cell/battery/ultracapacitor in electrical hybrid vehicle", International Journal of Hydrogen Energy, Vol.42, No.13, pp.8857-8869, 2017.

[18] A. Florescu, S. Bacha, I. Munteanu, A. I. Bratcu, and A. Rumeau, "Adaptive frequencyseparation-based energy management system for electric vehicles", Journal of Power Sources, Vol.280, pp.410-421, 2015.

[19] H. Yin, W. Zhou, M. Li, C. Ma, and C. Zhao, "An adaptive fuzzy logic-based energy management strategy on battery/ultracapacitor hybrid electric vehicles", IEEE Transactions on Transportation Electrification, Vol.2, No.3, pp.300-311, 2016.

[20] J. Jeong, N. Kim, W. Lim, Y. I. Park, S. W. Cha, and M. E. Jang, "Optimization of power management among an engine, battery and ultra-capacitor for a series HEV: A dynamic programming application", International Journal of Automotive Technology, Vol.18, No.5, pp.891-900, 2017.

[21] B. Wang, J. Xu, B. Cao, and X. Zhou, "A novel multimode hybrid energy storage system and its energy management strategy for electric vehicles", Journal of Power Sources, Vol.281, pp.432-443, 2015.

[22] K. Gokce and A. Ozdemir, "A rule based power split strategy for battery/ultracapacitor energy storage systems in hybrid electric vehicles", International Journal of Electrochemical Science, Vol.11, pp.1228-1246, 2016. 